\title{
COMMENTARY
}

\section{Delirium in the ICU: time to probe the hard questions}

\author{
Robert D Stevens ${ }^{* 1-4}$, Karin J Neufeld ${ }^{5}$ and Tarek Sharshar ${ }^{6}$ \\ See related research by Salluh et al., http://ccforum.com/content/14/6/R210
}

\begin{abstract}
Prevalent in critically ill patients, delirium remains poorly understood and difficult to treat. In a crosssectional study conducted in 12 countries, delirium was identified in close to one third of patients and was independently associated with increased mortality. While such epidemiological accounts represent an important cornerstone for research, scientific efforts are needed to elucidate the causes of delirium and the mechanisms underlying its association with poor outcomes.
\end{abstract}

Delirium affects a substantial proportion of hospitalized patients and increases their likelihood of unfavorable outcomes. This burden is especially high in critically ill populations in whom delirium is arguably the most prevalent form of organ dysfunction. In the previous issue of Critical Care, Salluh and colleagues [1] present the results of Delirium Epidemiology in Critical Care (DECCA), an international cross-sectional study evaluating the prevalence and short-term outcome of delirium in a sample of 232 patients admitted to 104 intensive care units (ICUs) across Latin America with two centers in Spain and the US. When patients were screened with the confusion assessment method for the ICU (CAM-ICU), delirium was identified in $32 \%$ of subjects and was associated with an adjusted threefold increase in ICU mortality and a greater than twofold increase in median ICU length of stay [1].

This study has the merit of evaluating delirium in a range of countries with diverse cultures and levels of

\footnotetext{
*Correspondence: rstevens@jhmi.edu

Departments of ${ }^{1}$ Anesthesiology and Critical Care Medicine, ${ }^{2}$ Neurology,

${ }^{3}$ Neurosurgery, and ${ }^{4}$ Radiology, Johns Hopkins University School of Medicine, 600 N. Wolfe Street, Baltimore, MD 21287, USA

Full list of author information is available at the end of the article
}

economic development and across a large number of medical institutions with heterogeneous practice patterns. The DECCA results reinforce the generalizability of findings from single-center observations [2,3] and closely match pooled prevalence and mortality estimates from a recently completed meta-analysis (RD Stevens, unpublished data). Inferences from DECCA are limited by the inability to account for pre-ICU neurological and cognitive status, the exclusion of a high proportion of potentially eligible patients because of concurrent sedation, and the absence of information on the underlying etiologies of delirium, on the treatments administered, or on the causes of death. Another limitation is that the SAPS3 (Simplified Acute Physiology Score) and SOFA (Sequential Organ Failure Assessment) scores, used here to adjust mortality risk in a multivariable model, can underestimate neurological failure indicating potential bias that would inflate adjusted odds ratios of death in delirious patients. Finally, as is the case with much delirium research, fundamental questions of nosology, mechanism, and causation are overlooked.

A central question is whether delirium, as it is currently defined [4,5], is a satisfactory construct. The spectrum of brain dysfunction encountered in hospitalized, acutely ill patients includes significant neurobehavioral abnormalities that fall outside the scope of this definition, either because sedation or coma prevented access to the patient's mental life, a problem that was encountered in DECCA, or because delirium criteria are not met [6]. Further work is warranted to rationalize the nosology of neurobehavioral syndromes associated with critical illness.

A second issue is that the underlying neural basis of delirium remains largely speculative. Many have argued that delirium is etiologically heterogeneous and pathobiologically complex, reflecting not a unified mechanism but an array of processes such as exposure to pharmacological agents with neuromodulatory effects, the actions of pro-inflammatory signaling molecules on the brain, or changes in neurotransmitter release and reuptake [7] - suggesting considerable obstacles to 
mechanistic research. However, recent advances in neuroimaging, neurophysiology, and biomarker analysis suggest powerful methods that will enhance our ability to probe brain-behavior relationships in delirium and potentially identify novel therapeutic targets [8].

A third question concerns the relationship between delirium and outcomes. Why are critically ill patients with delirium at increased risk of dying, even after adjustment in multivariable models? This independent relationship with mortality, found in several recent studies $[1-3,6,9,10]$, challenges widely held concepts of delirium as a reversible 'derivative' of disorders that are more serious. Recent research indicates a link between delirium in the ICU and cognitive dysfunction in the long term [11], and these data are consistent with observations of decreased cognitive performance among long-term survivors of critical illnesses such as acute respiratory distress syndrome [12] and severe sepsis [13]. The data are also consonant with results of a large prospective cohort that found a link between hospitalization, particularly involving ICU admission, and subsequent cognitive decline and even dementia [14]. It is certain that many patients survive the ICU without developing long-lasting neurological or behavioral sequelae. Collectively, however, available studies suggest that a subset of critically ill patients are at increased risk for chronic cognitive impairments that can have a dramatic impact on functional independence and quality of life [15]. Known as an indicator of acute - and often temporary brain dysfunction, delirium is also emerging, in selected cases, as a predictor of cognitive decline. But who are these 'selected cases'? Clearly, a research priority will be to develop tools to help answer this question.

In summary, abundant evidence indicates that delirium is a common and deadly complication of critical illness. Research must now aim to broaden knowledge on the biological mechanisms of delirium, unraveling its complex relationship to cognitive decline and mortality, with the goal of identifying effective protective and therapeutic interventions.

Abbreviations

DECCA, Delirium Epidemiology in Critical Care; ICU, intensive care unit.

\section{Competing interests}

The authors declare that they have no competing interests.

\section{Author details}

Departments of ${ }^{1}$ Anesthesiology and Critical Care Medicine, ${ }^{2}$ Neurology, ${ }^{3}$ Neurosurgery, ${ }^{4}$ Radiology, and ${ }^{5}$ Psychiatry and Behavioral Sciences, Johns
Hopkins University School of Medicine, 600 N. Wolfe Street, Baltimore, MD 21287, USA; ${ }^{6}$ Department of Intensive Care Medicine, Raymond Poincaré Teaching Hospital and University of Versailles Saint-Quentin en Yvelines, 104 Boulevard Raymond Poincaré, 92380 Garches, France.

Published: 4 February 2011

\section{References}

1. Salluh JI, Soares M, Teles JM, Ceraso D, Raimondi N, Nava VS, Blasquez P, Ugarte S, Ibanez-Guzman C, Centeno JV, Laca M, Grecco G, Jimenez E, AriasRivera S, Duenas C, Rocha MG; The DECCA (Delirium Epidemiology in Critical Care) Study Group: Delirium epidemiology in Critical Care (DECCA): an international study. Crit Care 2010, 14:R210.

2. Ouimet S, Kavanagh BP, Gottfried SB, Skrobik Y: Incidence, risk factors and consequences of ICU delirium. Intensive Care Med 2007, 33:66-73.

3. Lin S, Liu C, Wang C, Lin H, Huang C, Huang P, Fang Y, Shieh M, Kuo H: The impact of delirium on the survival of mechanically ventilated patients. Crit Care Med 2004, 32:2254-2259.

4. American Psychiatric Association: Diagnostic and Statistical Manual of Mental Disorders. 4th edition. Text revision. Washington, DC: American Psychiatric Association; 2000.

5. Inouye SK, van Dyck CH, Alessi CA, Balkin S, Siegal AP, Horwitz Rl: Clarifying confusion: the confusion assessment method. A new method for detection of delirium. Ann Intern Med 1990, 113:941-948.

6. Ely EW, Shintani A, Truman B, SperoffT, Gordon SM, Harrell FE Jr., Inouye SK, Bernard GR, Dittus RS: Delirium as a predictor of mortality in mechanically ventilated patients in the intensive care unit. JAMA 2004, 291:1753-1762.

7. Pustavoitau A, Stevens RD: Mechanisms of neurologic failure in critical illness. Crit Care Clin 2008, 24:1-24, vii.

8. Sharshar T, Carlier R, Bernard F, Guidoux C, Brouland JP, Nardi O, de la Grandmaison GL, Aboab J, Gray F, Menon D, Annane D: Brain lesions in septic shock: a magnetic resonance imaging study. Intensive Care Med 2007, 33:798-806

9. Shehabi Y, Riker RR, Bokesch PM, Wisemandle W, Shintani A, Ely EW: Delirium duration and mortality in lightly sedated, mechanically ventilated intensive care patients. Crit Care Med 2010, 38:2311-2318.

10. Thomason JW, Shintani A, Peterson JF, Pun BT, Jackson JC, Ely EW: Intensive care unit delirium is an independent predictor of longer hospital stay: a prospective analysis of 261 non-ventilated patients. Crit Care 2005, 9:R375-381.

11. Girard TD, Jackson JC, Pandharipande PP, Pun BT, Thompson JL, Shintani AK, Gordon SM, Canonico AE, Dittus RS, Bernard GR, Ely EW: Delirium as a predictor of long-term cognitive impairment in survivors of critical illness. Crit Care Med 2010, 38:1513-1520.

12. Hopkins RO, Weaver LK, Pope D, Orme JF, Bigler ED, Larson LV: Neuropsychological sequelae and impaired health status in survivors of severe acute respiratory distress syndrome. Am J Respir Crit Care Med 1999, 160:50-56.

13. Iwashyna TJ, Ely EW, Smith DM, Langa KM: Long-term cognitive impairment and functional disability among survivors of severe sepsis. JAMA 2010, 304:1787-1794.

14. Ehlenbach WJ, Hough CL, Crane PK, Haneuse SJ, Carson SS, Curtis JR, Larson EB: Association between acute care and critical illness hospitalization and cognitive function in older adults. JAMA 2010, 303:763-770.

15. Desai SV, LawTJ, Needham DM: Long-term complications of critical care. Crit Care Med 2010, Oct 14. [Epub ahead of print].

doi:10.1186/cc9971

Cite this article as: Stevens RD, et al.: Delirium in the ICU: time to probe the hard questions. Critical Care 2011, 15:118 